\title{
The Effect of Neuraxial Steroids on Weight and Bone Mass Density: A Prospective Evaluation
}

\author{
Laxmaiah Manchikanti, MD*, Vidyasagar Pampati, M Sc ${ }^{\#}$, Carla Beyer, RN ${ }^{\star \star}$, Kim Damron, $\mathbf{R N}^{\star \star}$, \\ Kim Cash, CRT•, and Tammy Moss, CRT•
}

The deleterious effects of corticosteroids utilized in neural blockade are a commonly discussed and contentious issue. Corticosteroids are considered to have widespread effects on almost all body systems, with suppression of the release of corticotropin (ACTH) from the pituitary suppressing the secretion of endogenous corticosteroids, thus producing a secondary adrenocortical insufficiency. Even though a multitude of complications of neuraxial steroids have been popularized, the more practical complications of corticosteroid administration are twofold - those resulting from withdrawal and those resulting from continued use of large doses. These mainly include suppression of the pituitary-adrenal axis, weight gain, osteopenia, osteoporosis, and a variety of other minor complications.

This prospective evaluation was undertaken to evaluate the effect of corticosteroids and the dose relationship on weight gain, bone-mass density (BMD), and other deleterious effects of steroids. The study population consisted of 204 patients; however, complete data were available on only 123 patients. These patients were divided into two groups, with group I receiving neural blockade without any steroids, and, Group II consisting of patients receiving neuraxial steroids. The results of serial determination of weight and BMD showed no significant change at any interval or at the end of 1 year in all 123 patients with or without steroid administration. In addition, this study also showed some improvement in BMD, as well as weight reduction indicating improvement in functional status.

It is concluded that low-dose administration of neuraxial steroids is safe in patients suffering with chronic pain who have failed to respond to conservative modalities of treatment with a favorable risk-benefit ratio. This study also showed no deleterious effect on weight or BMD.

Keywords: Corticosteroids, bone mass density, weight gain, neuraxial blockade, neuraxial steroids
Corticosteroids have been one of the most commonly used classes of agents in neuraxial blockade for the management of spinal pain since their introduction in 1952 (1-7). Other therapeutic agents used in neuraxial blockade include local anesthetic(s), opioid (s), Sarapin $®$, phenol, indomethacin, baclofen, hypertonic saline, and hyaluronidase; however, corticosteroids are the ones gaining the most attention and generating contentious arguments. The initial use of steroids in epidural injections was reported by Robechhi and Capra in 1952 (1) and Lievre and colleagues in 1953 (2). The initial American reports of epi-

From the Pain Management Center of Paducah, Paducah, Kentucky. *Dr. Manchikanti is the medical director. "Mr. Pampati is a statistician. **Ms. Beyer and Ms. Damron are clinical coordinators. Ms. Cash and Ms. Moss are radiological technologists. Address correspondence: Laxmaiah Manchikanti, MD, 2831 Lone Oak Road, Paducah, Kentucky 42003. Email: drm@apex.net dural steroid injections appeared in 1960 and 1961 (5-6) with extensive international literature (7). Initial systematic evaluation of intra-articular steroid injections for facet joint-mediated pain was reported by Mooney and Robertson in 1976 (8). Corticosteroids in neuraxial blockade have been postulated to reduce inflammation either by inhibiting the synthesis or release of a number of proinflammatory substances or by causing a reversible local anesthetic affect $(3,4)$. Various modes of action of corticosteroids include membrane stabilization, inhibition of neural peptide synthesis or action, blockade of phospholipase $\mathrm{A}_{2}$ activity; prolonged suppression of ongoing neuronal discharge, and suppression of sensitization of dorsal-horn neurons $(3,4,9-21)$.

Corticosteroids, whether administered orally, intramuscularly (IM), intravenously (IV), or neuraxially (by means of epidural, intrathecal or paraspinal injections), are considered to have widespread effects on almost all body systems, with suppression of the release of corticotropin 
(ACTH) from the pituitary, suppressing the secretion of endogenous corticosteroids and thus producing a secondary adrenocortical insufficiency. While numerous adverse effects have been attributed to the administration of corticosteroids $(3,4)$, review of the literature on epidural steroids or other types of neuraxial blockade reveals very few complications that can be directly attributed either to the chemistry or the pharmacology of the steroids $(3,4,7,22)$. While reports of neural toxicity have made headlines (2326), the more practical complications of corticosteroid administration are twofold those resulting from withdrawal and those resulting from continued use of large doses. This includes suppression of the pituitary-adrenal axis, weight gain, osteopenia, osteoporosis and multiple other complications $(3,4)$. While most of these complications are related to oral, IM, and IV administration of corticosteroids, some complications have been reported following utilization of neuraxial steroids. Various case reports of neuraxial blockade have dealt with hypothalamic - pituitary - adrenal (HPA) axis suppression during corticosteroid therapy and after its withdrawal and reported complications, including malaise, facial swelling, flattening of the face, scaly lesions of the scalp, Cushing's syndrome, and weight gain $(3,4,27-35)$. However, the major complications attributed to neuraxial corticosteroids are osteopenia, osteoporosis, weight gain and vertebral compression fractures (3, 4). Osteoporosis or osteopenia following neuraxial steroids used in the management of chronic pain, even though a frequently discussed problem, is uncommon. Similarly, weight gain and Cushing's syndrome are also commonly blamed on steroids, in spite of the fact that the evidence does not indicate whether weight gain is secondary to steroid administration or to the functional limitations of chronic pain.

There have not been any systematic evaluations of the use of neuraxial steroids and side effects related to susceptibility of infection, osteoporosis, osteopenia, edema, weight gain, and seizures. Hence, this evaluation was undertaken to evaluate the effect of corticosteroids and the influence of dose on weight gain, bone mass density (BMD), susceptibility to infection, edema, and seizure activity.

\section{METHODS}

The study population consisted of 204 patients followed at one private pain management practice in a non-university setting from 1998 through 2000. The patients were randomly selected by one of the nurse investigators from the pool of patients complaining of chronic pain and were assigned to one physician. Thus, the patients were ran- domly selected from a pool of patients and formed a consecutive group of patients seen by one physician. All the patients presented for pain management. During this period, 686 patients were evaluated.

The nature of the study and the potential hazards of the procedures and the drugs administered were explained to all patients, all of whom consented to participate. The patients were divided into two groups by patient choice, Group I receiving neural blockade without steroids. Group II consisted of patients receiving neuraxial steroids.

Evaluation of the patients included completion of a standard comprehensive pain management questionnaire, history, physical examination by a physician, and evaluation of the results of all procedures and investigations. Specific questions were asked with regards to steroid usage in the past, whether by means of neural blockade or otherwise.

Following the baseline evaluation, each patient underwent BMD evaluation, along with assessment of height and weight. The steroids administered in this study included methylprednisolone acetate (Depo-Medrol ${ }^{\circledR}$ ) and betamethasone sodium phosphate and betamethasone acetate (Celestone ${ }^{\circledR}$ Soluspan $\left.{ }^{\circledR}\right)$. Celestone Soluspan dosage was reported in equivalency of Depo-Medrol by converting $1.5 \mathrm{mg}$ of Celestone Soluspan to $10 \mathrm{mg}$ of DepoMedrol, $6 \mathrm{mg}$ of Celestone Soluspan being equivalent to $40 \mathrm{mg}$ of Depo-Medrol; and, finally, $18 \mathrm{mg}$ of Celestone Soluspan being equivalent to $120 \mathrm{mg}$ of Depo-Medrol. Neural blockade included caudal epidural injections; adhesiolysis; cervical, thoracic, lumbar and sacral transforaminal epidural injections; medial branch blocks of the cervical, thoracic, or lumbosacral spine; radiofrequency neurotomy; and intra-articular injections. When more than one region was involved, all the regions were treated in one session. The steroid dosage used 3 to $6 \mathrm{mg}$ of Celestone Soluspan for a caudal epidural, 1.5 to $3 \mathrm{mg}$ of Celestone Soluspan for each transforaminal level, 1 to $2 \mathrm{mg}$ of DepoMedrol for each level of medial branch blocks, and 10 to 40 $\mathrm{mg}$ of Depo-Medrol for intra-articular injections. In evaluating the amount of steroids administered prior to enrollment in this study, the same formula as described above was used for Celestone Soluspan, where as triamcinolone acetonide (Kenalog®) was considered equipotent to DepoMedrol.

All patients were monitored at 1, 3, 6, and 12 months, with monitoring of all the side effects under consideration, and repeat $\mathrm{BMD}$ evaluation at intervals of 3,6 , and 12 months. 
All the evaluations were performed at baseline at each visit by one of the registered nurses, and the BMD evaluation was performed by certified radiological technologists. Evaluation of alterations in physical status such as infection, edema, and seizures were also evaluated by the physician. The BMD evaluation was performed by a dualenergy X-ray absorptiometry (DXA) Osteometer DTX-200
(Osteometer-Meditech-Rodovre, Denmark) by measuring peripheral BMD.

Height was measured in inches and converted to centimeters for purposes of evaluation of body mass index (BMI). Weight was measured in pounds and was converted to kilograms for purposes of evaluation of BMI. Body mass

Table 1. Demographic characteristics

\begin{tabular}{|c|c|c|c|c|}
\hline & & Group I & Group II & $P$ value \\
\hline \multirow[b]{2}{*}{ Gender } & Male & $22 \%(5)$ & $34 \%(34)$ & \multirow[b]{2}{*}{0.325} \\
\hline & Female & $78 \%(18)$ & $66 \%(66)$ & \\
\hline \multirow{4}{*}{ Age (years) } & Mean \pm SEM & $51 \pm 3.13$ & $49 \pm 1.47$ & 0.558 \\
\hline & Range & $30-82$ & $23-88$ & - \\
\hline & $<65$ years & $70 \%$ & $83 \%(83)$ & \multirow[b]{2}{*}{0.153} \\
\hline & $\geq 65$ years & $30 \%(7)$ & $17 \%(17)$ & \\
\hline \multirow{2}{*}{$\begin{array}{l}\text { Duration of pain } \\
\text { (months) }\end{array}$} & Mean \pm SEM & $114 \pm 21.7$ & $85 \pm 8.3$ & 0.566 \\
\hline & Range & $6-454$ & $6-347$ & - \\
\hline \multirow{4}{*}{$\begin{array}{l}\text { Number of regions } \\
\text { involved }\end{array}$} & One region & $26 \%(6)$ & $20 \%(20)$ & \multirow{3}{*}{0.025} \\
\hline & Two regions & $22 \%(5)$ & $52 \%(52)$ & \\
\hline & Three regions & $52 \%(12)$ & $28 \%(28)$ & \\
\hline & Mean \pm SEM & $2.30 \pm 0.19$ & $2.09 \pm 0.07$ & 0.009 \\
\hline Weight (pounds) & Mean \pm SEM & $206 \pm 9.52$ & $175 \pm 4.66$ & 0.005 \\
\hline Height (inches) & Mean \pm SEM & $65.7 \pm 0.68$ & $66.6 \pm 0.37$ & 0.228 \\
\hline \multirow{4}{*}{ BMI } & Mean \pm SEM & $33.8 \pm 1.71$ & $27.7 \pm 0.66$ & 0.000 \\
\hline & Normal & $13 \%(3)$ & $37 \%(37)$ & \multirow{3}{*}{0.000} \\
\hline & Overweight & $13 \%(3)$ & $34 \%(34)$ & \\
\hline & Obese & $74 \%$ & $29 \%(29)$ & \\
\hline Diabetes & & $30 \%(7)$ & $6 \%(6)$ & 0.003 \\
\hline Hypothyroidism & & $17 \%(4)$ & $4 \%(4)$ & 0.004 \\
\hline Vertebral fracture & & $4 \%(1)$ & $1 \%(1)$ & 0.340 \\
\hline \multirow{4}{*}{ Therapy } & $\begin{array}{l}\text { Alendronate sodium } \\
\text { (Fosamax®) }\end{array}$ & $4 \%(1)$ & $2 \%(2)$ & 0.466 \\
\hline & Calcitonin Spray & $4 \%(1)$ & $0 \%$ & 0.187 \\
\hline & On hormone therapy & $35 \%(8)$ & $21 \%(21)$ & 0.179 \\
\hline & Mean \pm SEM & $0.4967 \pm 0.0236$ & $0.4940 \pm 0.0117$ & 0.920 \\
\hline \multirow{3}{*}{ BMD } & Normal & $61 \%(14)$ & $70 \%(70)$ & \multirow{3}{*}{0.549} \\
\hline & Osteopenia & $30 \%(7)$ & $19 \%(19)$ & \\
\hline & Osteoporosis & $9 \%(2)$ & $11 \%$ & \\
\hline
\end{tabular}

SEM : Standard error of mean 
Table 2. Status of patients in both groups based on steroid exposure, presence of diabetes mellitus, and hypothyroidism

\begin{tabular}{|c|c|c|c|c|c|c|c|}
\hline & & \multicolumn{2}{|c|}{ Steroid expos ure } & \multicolumn{2}{|c|}{ Diabetes mellitus } & \multicolumn{2}{|c|}{ Hypothy roidism } \\
\hline & & No & Yes & No & Yes & No & Yes \\
\hline \multirow[t]{2}{*}{ Number } & & 75 & 48 & 110 & 13 & 115 & 8 \\
\hline & $\begin{array}{l}\text { Mean } \\
\pm \text { SEM }\end{array}$ & $\begin{array}{l}28.6 \\
\pm 0.765\end{array}$ & $\begin{array}{l}29.2 \\
\pm 1.21\end{array}$ & $\begin{array}{l}28.3 \\
\pm 0.69\end{array}$ & $\begin{array}{l}33.2 \\
\pm 1.71\end{array}$ & $\begin{array}{l}28.6 \\
\pm 0.68\end{array}$ & $\begin{array}{l}31.2 \\
\pm 2.45\end{array}$ \\
\hline \multirow[t]{3}{*}{ BMI } & Normal & $29 \%(22)$ & $38 \%(18)$ & $34 \%(38)$ & $15 \%(2)$ & $33 \%(38)$ & $25 \%(2)$ \\
\hline & Overweight & $36 \%(27)$ & $21 \%(10)$ & $33 \%(36)$ & $8 \%(1)$ & $30 \%(35)$ & $25 \%(2)$ \\
\hline & Obese & $35 \%(26)$ & $42 \%(20)$ & $33 \%(36)$ & $77 \%(10)$ & $37 \%(42)$ & $50 \%(4)$ \\
\hline BMD & $\begin{array}{l}\text { Mean } \\
\pm \text { SEM }\end{array}$ & $\begin{array}{l}0.482 \\
\pm 0.013\end{array}$ & $\begin{array}{l}0.514 \\
\pm 0.017\end{array}$ & $\begin{array}{l}0.494 \\
\pm 0.011\end{array}$ & $\begin{array}{l}0.501 \\
\pm 0.031\end{array}$ & $\begin{array}{l}0.499 \\
\pm 0.011\end{array}$ & $\begin{array}{l}0.424 \\
\pm 0.029\end{array}$ \\
\hline $\begin{array}{l}\text { Osteoporosis/ } \\
\text { Osteopenia }\end{array}$ & & $33 \%(25)$ & $29 \%(14)$ & $32 \%(35)$ & $31 \%(4)$ & $30 \%(35)$ & $50 \%(4)$ \\
\hline
\end{tabular}

index was calculated using the formula of weight and kilograms divided by height and meters squared $\left(B M I=k g / \mathrm{m}^{2}\right)$.

The patient's age was calculated from his or her birth date, whereas duration of pain was calculated based on the patient's memory of the onset of pain to the closest month, when available. Bone mass density was evaluated by mean distal BMD grams per centimeters squared. The T-score was used for the diagnosis of osteoporosis or osteopenia. Osteoporosis and osteopenia were calculated based on World Health Organization's criteria based on T-scores (36). A value for BMD or bone mineral content that is not more than -1 standard deviation (SD) below the young adult mean value is considered as normal, a value between -1 and $-2.5 \mathrm{SD}$ is considered as osteopenia or a low bone mass, a value of more than -2.5 SD below the young adult mean value is considered osteoporosis, and a value more than $-2.5 \mathrm{SD}$ below the young adult mean value in the presence of one or more fragility fractures is considered as severe or established osteoporosis (37).

Data were recorded on a database using Microsoft $\AA$ Access ${ }^{\circledR}$. The SPSS version 9.0 statistical package was used to generate the frequency tables. chi-square statistics were used to test the significant difference between groups. Fisher's exact test was used whenever the expected value was less than 5. Student's ' $t$ ' test was used to test the mean difference between groups. A BMI of 25 to 29.9 was considered overweight, while a BMI of 30 or over was considered as obese. Results were considered statistically significant if the $P$-value was less than 0.05 .

\section{RESULTS}

Of the 204 patients enrolled initially, 123 patients completed the study with all data available. Eighteen of the original 204 patients were managed conservatively and discharged. Of the remaining 63 patients, 42 patients improved with treatment within 3 to 6 months, did not receive continued treatment, and were unavailable for follow-up at the end of 1 year. The remaining 20 patients dropped out of the treatment program and were lost to follow-up. Thus, results were tabulated for the 123 patients with complete data.

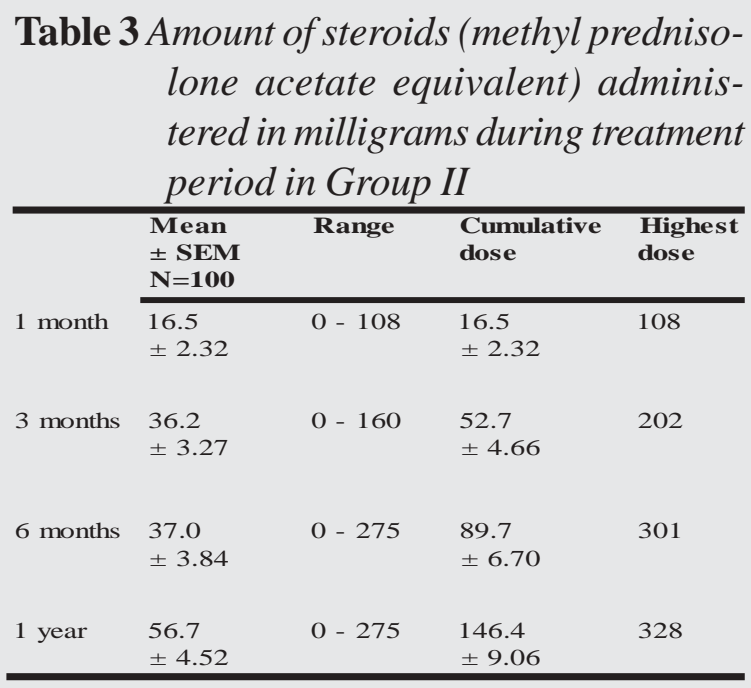

SEM: Standard Error of Mean 
Table 4 Results of serial determinations of BMD

\begin{tabular}{lcccc}
\hline & \multicolumn{2}{c}{ Group I } & \multicolumn{2}{c}{ Group II } \\
\cline { 2 - 5 } & Mean \pm SEM & Interval change & Mean \pm SEM & Interval change \\
Baseline & $0.4967 \pm 0.0236$ & - & $0.4940 \pm 0.0116$ & - \\
3 months & $0.4952 \pm 0.0233$ & -0.0015 & $0.4909 \pm 0.0110$ & -0.0031 \\
6 months & $0.5086 \pm 0.0269$ & 0.0134 & $0.4911 \pm 0.0111$ & 0.0002 \\
1 year & $0.5000 \pm 0.0256$ & -0.0086 & $0.4917 \pm 0.0112$ & 0.0006 \\
Total change & - & 0.0033 & - & -0.0023 \\
\hline
\end{tabular}

SEM: Standard error of mean

\section{Patient Demographics}

Patient demographics describing gender distribution, age, duration of pain, number of regions involved, presence or absence of diabetes mellitus, presence or absence of vertebral fracture, and history of prior steroid administration are listed in Table 1. There were no significant differences noted among the groups with regards to gender, age, duration of pain, height, incidence of vertebral fracture, therapy for low BMD, and various levels of BMD. However, patients in Group I weighed more and had a higher BMI, and a greater proportion of patients were diabetic and hypothyroid in Group I. The mean number of regions involved was also higher for Group I.

\section{Baseline Status}

Baseline status of all patients in both groups with regards to the administration of steroids prior to enrolling in the study, presence of diabetes mellitus and hypothyroidism, BMI, BMD, and presence of vertebral fracture was evaluated (Table 2). There were no significant differences noted in any of these aspects except that diabetics had a higher mean BMI. The results showed prior exposure of steroids in $39 \%$ of the patients, with total dosages ranging from 30

Table 5 Effect of prior exposure to steroids on incidence of low BMD (Osteoporosis/Osteopenia)

\begin{tabular}{llll}
\hline \multirow{2}{*}{ Prior steroids } & \multicolumn{2}{l}{ Osteoporosis/Osteopenia } \\
\cline { 2 - 3 } & Positive & Negative & Total \\
\hline Yes & $29 \%(14)$ & $71 \%(34)$ & $39 \%(48)$ \\
No & $33 \%(25)$ & $67 \%(50)$ & $61 \%(75)$ \\
Total & $32 \%(39)$ & $68 \%(84)$ & $100 \%(123)$ \\
\hline
\end{tabular}

$\mathrm{mg}$ to $5000 \mathrm{mg}$. Diabetes and hypothyroidism were seen in $11 \%$ and $7 \%$ of the patients, respectively.

\section{Steroid Administration}

The data were tabulated with regards to the amount of steroids administered during treatment for 1 year at each level at intervals of 1,3,6 months and 1 year, along with cumulative doses at the same intervals for Group II as shown in Table 3. The mean cumulative Depo-Medrol dosage for 1 year was $146.4 \mathrm{mg} \pm 9.06$, with a highest dose of $328 \mathrm{mg}$.

\section{BMD Evaluation}

Results of serial determination of BMD are shown in Table 4 at baseline, 3 months, 6 months, and 1 year demonstrating the mean, as well as range, of peripheral BMD, with interval changes. The interval and total changes were minor and insignificant.

Calculation of change in BMD over a period of 1 year in all patients based on whether they had received steroids prior to enrollment in the study, as well as steroid adminis-

Table 6 Effect of steroids on decrease of low BMD (Osteoporosis/Osteopenia)

\begin{tabular}{llll}
\hline & Positive & Negative & No change \\
\cline { 2 - 4 } Group I & $0 \%$ & $4 \%$ & $96 \%$ \\
Group II & $2 \%$ & $7 \%$ & $91 \%$ \\
\hline
\end{tabular}

Positive: Only patients who became positive at the end but were negative initially

Negative: Only patients who became negative at the end but were positive initially

No change: Only patients who had no change at initial and final measurements 
Table 7. Results of serial determinations of weight in pounds

\begin{tabular}{|c|c|c|c|c|c|c|}
\hline & & Group I & & & Group II & \\
\hline & Mean \pm SEM & Range & Mean change & Mean \pm SEM & Range & Mean change \\
\hline Baseline & $206.1 \pm 9.52$ & $90-284$ & - & $175.1 \pm 4.66$ & $97-320$ & - \\
\hline 1 month & $206.1 \pm 9.82$ & $90-284$ & 0.0 & $174.7 \pm 4.62$ & $97-320$ & -0.4 \\
\hline 3 months & $204.3 \pm 9.70$ & $90-285$ & -1.8 & $173.4 \pm 4.63$ & $96-320$ & -1.3 \\
\hline 6 months & $204.6 \pm 9.47$ & $91-279$ & 0.3 & $173.1 \pm 4.55$ & $95-320$ & -0.3 \\
\hline 1 year & $204.4 \pm 8.51$ & $92-260$ & -0.2 & $173.2 \pm 4.68$ & $84-326$ & 0.1 \\
\hline Total change & & & -1.7 & & & -1.9 \\
\hline
\end{tabular}

tration during the study, showed no significant differences.

A 2 x 2 contingency table was constructed to evaluate the effect of prior exposure of steroids on decrease in BMD resulting in osteoporosis and osteopenia (Table 5). This showed no significant difference among patients who had received steroids compared to those who had not.

Additionally, a 2 × 2 table constructed to evaluate the effect of steroid administration during evaluation over a period of 1 year on BMD (osteoporosis and osteopenia) demonstrated a change from baseline to end of 1 year (Table $6)$. This analysis showed that there was no significant deterioration or decrease associated with the administration of steroids. In fact, this evaluation showed an increase in BMD and a decrease in the proportion of patients with low BMD.

Further, the relationship of steroids to changes in BMD was calculated, with no significant changes noted.

\section{Weight}

As shown in Table 7, serial determinations of weight were tabulated at baseline, 1 month, 3 months, 6 months, and 1 year in both groups, evaluating range and mean weight along with change. The results showed no significant differences, even though there were slight decreases in both groups.

The effect of steroids on weight is shown in Table 8. There was no change noted between groups. Overall $43 \%$ of the patients showed some weight gain in Group I, in contrast to $33 \%$ in Group II, weight loss was seen in $57 \%$ and $67 \%$ of the patients in groups I and II, respectively. However, as shown in Table 8, there was insignificant, but mild decrease in weight in both groups.

\section{Other Effects}

All patients were evaluated for signs of infection, development of edema, and seizure activity. These complications were not noted in any of the patients.

\section{DISCUSSION}

Osteoporosis is a systemic disorder characterized by decreased bone mass and microarchitectural deterioration of bone tissue leading to bone fragility and increased susceptibility to fractures of hip, spine, and wrist. Osteoporosis has been classified either as a primary or a secondary form, with primary osteoporosis (which is most commonly seen) being secondary to typical, age-related loss of bone from the skeleton (38). In contrast, secondary osteoporosis re-

Table 8: Effect of steroids on weight change

\begin{tabular}{llllllll}
\hline & \multicolumn{3}{c}{ Weight loss in pounds } & & \multicolumn{3}{c}{ Weight gain in pounds } \\
\cline { 2 - 3 } Group I & $\geq 10$ & 10 to 5 & 5 to 1 & & 1 to 5 & 5 to 10 & $>10$ \\
Group II & $23 \%(8)$ & $9 \%(2)$ & $13 \%(3)$ & & $13 \%(3)$ & $9 \%(2)$ & $21 \%(5)$ \\
\hline
\end{tabular}


sults from the presence of other diseases or conditions that predispose to bone loss and is associated with a variety of factors, including hormonal imbalances, cancer, gastrointestinal disorders, drug use (including corticosteroids), cancer chemotherapy, anticonvulsants, heparin, barbiturates, valproic acid, and gonadotropin-releasing hormone (38). Other factors include excessive use of aluminumcontaining antacids, chronic renal failure, hyperthyroidism, hypogonadism in men, immobilization, osteogenesis imperfecta and related disorders, inflammatory arthritis, and poor nutrition (39).

Secondary osteoporosis occurs equally in men and women and at any age. In various series of osteoporotic patients, secondary osteoporosis accounts for about $40 \%$ of the total number of osteoporotic fractures (40). Among druginduced suspects, long-term corticosteroid use is alleged to be associated with osteoporosis and to be one of the most frequent, serious, and long-lasting side effects of corticosteroid administration $(41,42)$. It also has been stated that osteoporosis may be a preventable side effect of corticosteroid treatment if appropriate preventive measures are taken (43). The American College of Rheumatology released guidelines for the prevention of glucocorticoid-induced osteoporosis in 1996 (44). The guidelines suggested a baseline measurement of bone density before initiating long-term corticosteroid treatment, as well as repeat measurements to assess bone loss. However, it is not clear whether the administration of neuraxial steroids is included in the category of long-term administration of corticosteroids or not. In addition, we are not aware of any studies evaluating the effect of neuraxial steroids on BMD. This study shows that, in low doses, neuraxial steroids are not deleterious and are not shown to cause any significant deterioration in BMD, causing either osteopenia or osteoporosis. Glucocorticoid-induced osteoporosis is secondary to disruption of calcium balance and decrease in calcium supply by reducing intestinal, and renal tubular absorption. While most steroid effects on calcium absorption are dose dependent, multiple other factors subject to broader influences also influence calcium metabolism in osteoporosis. Major risk factors for glucocorticoid-induced osteoporosis include total cumulative dose of glucocorticoid, ages less than 15 years or greater than 50 years, and postmenopausal status (45). However, in this evaluation, we were unable to find any significant difference in elderly patients compared to patients who were younger than 65 years of age. Aseptic necrosis of the bone (osteonecrosis) may also complicate long-term therapy with glucocorticoids and has also been reported following short courses with high doses. The femoral head is most often involved, but other lower joints may also be affected $(37,46)$. Thus far, no studies have shown that such a relationship exists between steroids used in neural blockade and osteoporosis or avascular necrosis. There was no evidence of deterioration in $\mathrm{BMD}$, development of osteopenia, or osteoporosis in this evaluation with two groups, either in the group with steroid administration over a period of 1 year, or without steroid administration. In addition, this evaluation also showed a small increase in BMD, converting $4 \%$ of the patients who presented with low BMD in Group I to the negative category, with an increased BMD, along with $7 \%$ of the patients in group II who were initially positive for low BMD but changed to negative status at the end of 1 year. In contrast, only $2 \%$ of the patients who were negative initially became positive at the end of 1 year in Group II and $0 \%$ of the patients in Group I. A predominant proportion of patients showed no significant change $(96 \%$ in Group I and 91\% in Group II). In addition, the present evaluation failed to show any gross evidence of avascular necrosis of the femoral head. This study also failed to show any effect of prior exposure to steroids on incidence of low BMD or osteopenia (Table 5). This study showed that $39 \%$ of the patients were exposed to steroids prior to enrolling in the study, however, there was no significant difference in incidence of low BMD compared to the patients who had not received any steroids prior to enrolling in the treatment program. In addition, we were also unable to demonstrate any relationship between dosage and the intervals of administration and BMD, but it is important to remember that the dosages of steroids used in the study are considered to be low.

Obesity is a serious medical problem that is increasingly prevalent, affecting millions, and of great interest to the public $(39,47)$. Obesity has been associated with symptoms such as adverse fat distribution, and secondary disorders including coronary artery disease, stroke, non-insulin dependent diabetes mellitus, cancer, and low back pain (48). Obesity, defined as being $30 \%$ over the ideal weight, influences normal body mechanics by making it more difficult to sit, stand, and walk and increases the time required to recover from an injury. Fatty tissue is a stress on the body even when a person is not injured, as it decreases the blood flow - carrying nutrients for healing to injured areas (48). Since it is well known that too much fat is associated with loss of endurance, it is presumed that obesity also makes rehabilitation more difficult for low back injury patients since poor endurance and soon cardiovascular fitness may hinder full participation in therapy (48). While obesity is a possible risk factor for low back pain, any type of weight gain is considered to be deleterious to any type 
of chronic pain patient (48). Weight gain secondary to the suppression of the pituitary-adrenal axis is mostly related to oral, IM, and IV administration of corticosteroids. However, there are also multiple reports of weight gain and Cushing's syndrome appearing after the use of neuraxial steroids $(3-4,7,32-35)$. The present study showed no correlation between the neuraxial steroids, either individual doses or cumulative doses, and obesity, as there was no weight gain. In fact, this study showed a mean decrease of weight of $1.7 \mathrm{lbs}$ in Group I and $1.9 \mathrm{lbs}$ in Group II. In addition, this study also demonstrated that some amount of weight gain was seen in $43 \%$ of the patients in Group I and $33 \%$ of the patients in Group II, whereas weight loss was seen in 57\% of the patients in Group I and $67 \%$ of the patients in Group II. Weight gain of greater than $10 \mathrm{lbs}$ was seen in $21 \%$ of the patients in group I without any steroids and $13 \%$ of the patients with steroid administration, whereas weight loss of greater than $10 \mathrm{lbs}$ was seen in 35\% of the patients in Group I and 23\% of the patients in Group II. This may be explained by the fact that, with improvement in the pain status, functional status increases, consequently resulting in some decrease in weight. We were also unable to demonstrate any significant relationship between either the dosage or the frequency of steroids on weight, similar to the effect on the BMD.

Side effects related to the endocrine system with adrenal suppression and subsequent complications also have been major problems with neuraxial steroids. The use of corticosteroids repeatedly for days or even for a few weeks does not lead to adrenal insuffiencey upon stopping treatment, but prolonged therapy with corticosteroids may result in suppression of the pituitary-adrenal function that can be slow in returning to normal. HPA axis suppression during corticosteroid therapy and after its withdrawal has been extensively studied (27-45). Even though adrenal suppression was not evaluated by serum cortisone levels, etc., no gross evidence of Cushing's syndrome was observed in this evaluation. Once again, not only were there no gross changes, but there was no evidence of adrenal suppression or Cushing's syndrome based on either the dosage or the frequency of administration. In addition, it has also been stated that hyperthyroidism may predispose patients to low BMD, whereas hypothyroidism and diabetes may protect them against low BMD. In this study, we were unable to identify any significant differences between groups in relation to the presence of diabetes or hypothyroidism, and high or low BMD.

The pathophysiology of chronic spinal pain is a complex phenomenon with resultant functional deficiencies, and inactivity, along with psychosocial problems resulting in weight gain and loss of bone density related to inactivity. The current study was designed to determine some of the important and practical side effects of neuraxial steroids. The study was also conducted with and without steroids and only in patients suffering with chronic spinal pain who failed to respond to conservative, as well as invasive, modalities of treatment including surgical interventions. The patients in this study group had suffered with chronic, disabling pain on the average of 7 to 10 years. Following management with neuraxial blockade, a significant proportion of these patients achieved meaningful improvement in pain and functional status.

The follow-up period in this study may be criticized for being too short for assessing the long-term effects of corticosteroids; however, the length of follow-up period is appropriate for this type of therapy. Apparently, neuraxial steroid therapy is associated with minimal morbidity, even though this type of therapy is considered invasive, though much less invasive than surgical interventions. In addition, most reported complications with corticosteroids have been observed within the initial 2 to 8 weeks after administration.

Further criticism may be directed at the lack of laboratory evaluations to measure adrenal suppression. However, there was no clinical evidence of Cushing's syndrome in any of the patients. This type of evaluation is not only clinically extremely difficult but also financially not feasible. Nevertheless, this study does answer some of the practical issues related to neuraxial blockade. The doses administered in this study are not typical in clinical practices. In addition, frequency and total number of injections are controversial and poorly addressed issues in neural blockade. Limitations of steroid administration by experts have varied significantly over the years. These have included limitations of $3 \mathrm{mg} / \mathrm{kg}$ body weight of steroid or $210 \mathrm{mg} /$ year in an average person; three injections in a series irrespective of the patient's progress or lack thereof, which will translate into $120 \mathrm{mg}$ of Depo-Medrol at $40 \mathrm{mg}$ each dose and $360 \mathrm{mg}$ if $120 \mathrm{mg}$ each treatment is used; three injections followed by a repeat course of three injections after 3-, 6-, or 12-month intervals that will range in steroid dosages from $120 \mathrm{mg}$ to $1440 \mathrm{mg} / \mathrm{year}$ if only one region of the body is treated; and some have reported six injections if they are of benefit, not to exceed three if they are not beneficial; up to 10 injections by others; and, finally, no limitation in terms of number or dosage. The results of this study will apply only for the dosages utilized in this study, which included the treatment of mul- 
tiple regions over a period of 1 year with low-dose corticosteroids. Extrapolation of these results for much higher dosages is not warranted, and further studies are needed.

Finally, criticism may be directed at the nonblinded nature of the study, even though this was prospective and randomized. Both the physician and the patient were aware of the type of treatment, as well as potential adverse effects. However, once again, the issues of ethics, feasibility, cost, and reliability pose challenges to the double-blind trial, which theoretically represents the "gold standard" (4954). Further, in a recent analysis by Concato and coworkers (55) analyzing 99 reports for five clinical topics, the well-designed observational studies do not systematically overestimate the magnitude of effects of treatments as compared with those in randomized, controlled trials on the same topic. However, this is not to undermine the importance of randomized, double-blinded, controlled studies. Flaws can exist in a study design or analysis, both in open as well as blinded trials.

\section{CONCLUSION}

Based on the results of the present study, it is concluded that low-dose administration of neuraxial steroids is safe in patients suffering with chronic pain who fail to respond to conservative modalities of treatment with a favorable risk-benefit ratio. The present study evaluated deleterious effects of corticosteroid administration in the short term, as well as over a period of 1 year on multiple aspects, specifically BMD and weight gain, which are shown to be the pivotal side effects of neuraxial steroids. It is concluded that neuraxial steroids in the doses administered in this study, either in the form of a single dose or cumulative doses, do not cause significant weight gain or deterioration in BMD. Other complications were also not observed in this study; however, issues requiring further qualification include the exact relationship between the administered dose of steroids and the resultant deleterious effects on a long-term basis, namely significantly higher doses as seen in some clinical practices. Considering that these patients have suffered with chronic pain for several years and have failed to respond to conservative modalities of treatment, continued usage of neuraxial steroids, while awaiting further studies, appears to be justified.

\section{REFERENCES}

1. Robechhi A, Capra R, L'idrocortisone. Prime esperienze cliniche in campo reumatologico. Minerva Med 1952; 98:1259-1263.
2. Lievre JA, Block-Michel H, Pean G et al. L'hydrocortisone en injection locale. Rev Rhumat Mal Osteoartic 1953; 20:310-311.

3. Manchikanti L. The value and safety of steroids in neural blockade, part I. AJPM 2000; 10:69-78.

4. Manchikanti L. The value and safety of steroids in neural blockade, part II. AJPM 2000; 10:122-134.

5. Brown JH. Caudal anesthesia and back manipulation. Northwest Med (Seattle) 1960; 59:905-909.

6. Goebert HW, Jallo SJ, Gardner WJ et al. Painful radiculopathy treated with epidural injections of procaine and hydrocortisone acetate results in 113 patients. Anesth Analg 1961; 140:130-134.

7. Bogduk N, Christophidis N, Cherry D et al. Epidural use of steroids in the management of back pain. Report of working party on epidural use of steroids in the management of back pain. National Health and Medical Research Council Commonwealth of Australia, Canberra 1994:pp1-76.

8. Mooney V, Robertson J. The facet syndrome. Clin Orthop 1976; 115:149-156.

9. Fowler RJ, Blackwell GJ. Anti-inflammatory steroid induced biosynthesis of a phospholipase $\mathrm{A}_{2}$ inhibitor which prevents prostaglandin generation. Nature 1979; 278:456-459.

10. Devor M, Govrin-Lippmann R, Raber P. Corticosteroids suppress ectopic neural discharges originating in experimental neuromas. Pain 1985; 22:127-137.

11. Husa SY, Chen YZ. Membrane receptor mediated electrophysiological effects of glucocorticoid on mammalian neurons. Endocrinology 1989; 124:687-691.

12. Johansson A, Hao J, Sjolund B. Local corticosteroid application blocks transmission in normal nociceptor C-fibers. Acta Anaesthesiol Scand 1990; 34:335-338.

13. Faver LE, Wakim NG, Duhring JL. Evolving concepts in mechanism of steroid action: Current developments. Am J Obstet Gynecol 1987; 156:1449-1458.

14. Olmarker K, Byrod G, Cornefijord M et al. Effects of methylprednisolone on nucleus pulposus-induced nerve root injury. Spine 1994; 19:1803-1808.

15. Nicol GD, Klinberg DK, Vasko MR. Prostaglandin E2 enhances calcium conductance and stimulates release of substance $\mathrm{P}$ in avian sensory neurons. $J$ Neurosci 1992; 12:1917-1927.

16. Coderre $\mathrm{T}$. Contribution of protein kinase $\mathrm{C}$ to central sensitization and persistent pain following tissue injury. Neurosci Lett 1992; 140:181-184.

17. Hayashi N, Weinstein JN, Meller ST et al. The effect of epidural injection of betamethasone or bupivacaine in a rat model of lumbar radiculopathy. Spine 1998; 23:877-885.

18. Lee HM, Weinstein JN, Meller ST et al. The role of steroids and their effects on phospholipase A2. An animal model of radiculopathy. Spine 1998; 23:11911196. 
19. Minamide A, Tamaki T, Hashizume H et al. Effects of steroids and lipopolysaccharide on spontaneous resorption of herniated intervertebral discs. An experience study in the rabbit. Spine 1998; 23:870-876.

20. Johansson A, Bennett GJ. Effect of local methylprednisolone on pain in a nerve injury model. A pilot study. Reg Anesth 1997; 22:59-65.

21. Kingery WS, Castellote JM, Maze M. Methylprednisolone prevents the development of autotomy and neuropathic edema in rats, but has no effect on nociceptive thresholds. Pain 1999; 80:555-556.

22. Manchikanti L, Singh V, Bakhit C et al. Interventional techniques in the management of chronic pain: Part 1.0. Pain Physician 2000; 3:7-42.

23. Nelson D. Dangers from methylprednisolone acetate therapy by intraspinal injection. Arch Neurol 1988; 45:804-806

24. Wilkinson HA. Intrathecal Depo-Medrol. A literature review. Clin J Pain 1992; 8:49-56.

25. Corrigan AB, Carr G, Tugwell S. Intraspinal corticosteroid injections. Med J Aust 1982; 1:224-225.

26. Bogduk N, Cherry D. Epidural corticosteroid agents for sciatica. Med J Aust 1985; 143:402-406.

27. McEvoy GK, Litvak K, Welsh OH et al. AHFS-99 drug information. Bethesda, American Society of Health-System Pharmacists 1999; 2636-2662.

28. Mikhail GR, Livingood CS, Mellinger RC et al. Effect of long-acting parenteral corticosteroids on adrenal function. Ann Allergy 1973; 31:337-343.

29. Mikhail GR, Livingood CS, Mellinger RC et al. Effect of long-acting parenteral corticosteroids on adrenal function. Arch Dermatol 1969; 100:263-268.

30. Schimmer BP, Parker KL. Adrenocorticotropic hormone; adrenocortical steroids and their synthetic analogs; inhibitors of the synthesis and actions of adrenocortical hormones. IN: Hardman JG, Molionoff PB, Ruddon RW (ed). Goomanís \& Gilmanís, The pharmacological basis of therapeutics. $9^{\text {th }}$ ed. New York: McGraw-Hill, 1996: 1459-1485.

31. Melby JC. Drug spotlight program: Systemic corticosteroid therapy; Pharmacologic and endocrinologic considerations. Ann Intern Med 1974; 81:505-512.

32. Knight CL, Burnell JC. Systemic side-effects of extradural steroids. Anaesthesia 1980; 35:593-594.

33. Stambough JL, Booth RE, Rothman RH. Transient hypercorticism after epidural steroid injection. J Bone and Joint Surg 1984; 66-A:1115-1116.

34. Tuel SM, Meythaler JM, Cross LL. Cushing's syndrome from epidural methylprednisolone. Pain 1990; 40:81-84

35. Edmonds LC, Vance ML, Hughes JM. Morbidity from paraspinal Depo-Corticosteroid injections for analgesia. Cushing's syndrome and adrenal suppression. Anesth Analg 1991; 72:820-822.

36. WHO Technical Report Series 843: Assessment of Fracture Risk and its Application to Screening for Postmenopausal Osteoporosis. Geneva, World Health
Organization, 1994.

37. Kelman GJ, Williams GW, Colwell CW et al. Steroidrelated osteonecrosis of the knee. Clin Orthop 1990; 257:171-176.

38. Iqubal MM. Osteoporosis: Epidemiology, diagnosis, and treatment. Southern Med J 2000; 93:2-19.

39. Allison DB, Fontaine KR, Manson JE et al. Annual deaths attributable to obesity in the United States. JAMA 1999; 282:1530-1538.

40. Gallagher JC. Osteoporosis. Conn's Current Therapy. Robert ER (ed). Philadelphia, WB Saunders Co, 1999, pp 590-594.

41. Saag K, Koehnke R, Caldwell J et al. Low dose longterm corticosteroid therapy in RA: An analysis of serious adverse events. Am J Med 1994; 96:115-123.

42. Peel NF, Moore DJ, Barrington NA et al. Risk of vertebral fracture and relationship to bone mineral density in steroid treated rheumatoid arthritis. Ann Rheum Dis 1995; 54:810-816.

43. Buckley L, Marquez M, Feezor R et al. Prevention of corticosteroid-induced osteoporosis. Arthritis \& Rheumatism 1999; 42:1736-1739.

44. American College of Rheumatology Task Force on Osteoporosis Guidelines. Recommendations for the prevention and treatment of glucocorticoid-induced osteoporosis. Arthritis Rheum 1996; 39:1791-1801.

45. Healey JH. Glucocorticoid-induced osteoporosis. Current Opinion in Orthopedics 1994; 5:33-38.

46. Mankin HJ. Nontraumatic necrosis of bone (osteonecrosis). N Engl J Med 1992; 326:1473-1479.

47. Flegal KM, Carroll MD, Kuczmarksi RJ et al. Overweight and obesity in the United States. Prevalence and trends. 1960-1994. Int J Obes Relat Metab Disord 1998; 22:39-47.

48. Manchikanti L. Epidemiology of low back pain. Pain Physician 2000; 3:167-192.

49. Turner JA, Loeser JD, Bell KG. Spinal cord stimulation for chronic low back pain. A systematic literature synthesis. Neurosurgery 1995; 37:1088-1098.

50. Weinstein JN. The tortoise and the hare. Is there a place in spine surgery for randomized trials? Spine 1999; 23:2548-2549.

51. Winter RB. The prospective, randomized, controlled clinical trial in spine surgery. Fact or fiction? Spine 1999; 23:2550-2552.

52. Carey TS. Randomized controlled trials in surgery. An essential component of scientific progress. Spine 1999; 23:2553-2555.

53. Fairbank J. Randomized controlled trials in the surgical management of spinal problems. Spine 1999; 23:2556-2563.

54. Tosteson TD. Point of view. Spine 1999; 24:25622563.

55. Concato J, Shah N, Horwitz R. Randomized, controlled trials, observational studies, and the hierarchy of research designs. N Engl J Med 2000; 342:18871892. 